\title{
The choice of droplet size probability distribution function for oil spill modeling is not trivial
}

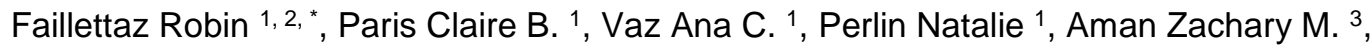 \\ Schlüter Michael ${ }^{4}$, Murawski Steven A. ${ }^{5}$
}

\author{
1 University of Miami, Rosenstiel School of Marine and Atmospheric Science, FL 33149, Miami, USA \\ 2 Ifremer, STH, F-56100 Lorient, France \\ ${ }^{3}$ Centre for Energy, School of Mechanical and Chemical Engineering, The University of Western \\ Australia, Crawley 6009, WA, Australia \\ ${ }^{4}$ Institute of Multiphase Flows, Hamburg University of Technology, Eißendorfer Straße 38, 21073 \\ Hamburg, Germany \\ ${ }^{5}$ University of South Florida, College of Marine Science, 140 7th Ave. S., St. Petersburg, FL 33701, \\ USA \\ *Corresponding author : Robin Faillettaz, email address : robin.faillettaz@ifremer.fr
}

\begin{abstract}
:
The droplet size distribution (DSD) formed by gas-saturated oil jets is one of the most important characteristics of the flow to understand and model the fate of uncontrolled deep-sea oil spills. The shape of the DSD, generally modeled as a theoretical lognormal, Rosin-Rammler or non-fundamental distribution function, defines the size and the mass volume range of the droplets. Yet, the fundamental DSD shape has received much less attention than the volume median size (d50) and range of the DSD during ten years of research following the Deepwater Horizon (DWH) blowout. To better understand the importance of the distribution function of the droplet size we compare the oil rising time, surface oil mass, and sedimented and beached masses for different DSDs derived from the DWH literature in idealized and applied conditions, while keeping d50 constant. We highlight substantial differences, showing that the probability distribution function of the DSD for far-field modeling is, regardless of the $\mathrm{d} 50$, consequential for oil spill response.
\end{abstract}

\section{Highlights}

- The importance of the oil droplet size distribution function was not known. The distribution function of the DSD drives the oil mass distribution patterns. First response should consider different d50s and probability distribution functions.

Keywords : Droplet size distribution, DSD, Oil spill, Oil spill model, Oil model, Deepwater Horizon, Blowout, d50, Probability distribution function 
36 The droplets sizes are key characteristics to predict the transport and fate of uncontrolled deep-sea

37 oil spills. The 2010 Deepwater Horizon (DWH) blowout released an estimated five million barrels

38 of live oil into the northern Gulf of Mexico (GoM), impacting the beaches and seafloor (Nixon et al.

39 2016, Romero et al. 2017). Studies had previously focused on the volume median size of oil

40 droplets (d50) to understand its effect on emulsion stability (Tambe and Sharma 1994) and,

41 immediately after the DWH, on the timing and amount of oil surfacing (Ryerson et al. 2012). Ten

42 years later, there is still an ongoing debate on the correct d50 of the DWH oil droplets, since the d50

43 estimated at the time of the spill was a decisive factor for the unprecedented use of sub-sea

44 dispersant injection as a response strategy (Paris et al. 2018). Droplet size distribution (DSD)

45 estimates have thus been the focus of numerous analytical models, such as dynamical models (Zhao

46 et al. 2014, 2016, Gros et al., 2017) or equilibrium models with modified Weber number (Johansen

47 et al., 2013, Li et al. 2017) and of laboratory work under normal atmospheric conditions and

48 temperature using the Ohmsett tank (Zhao et al. 2016) and under high-pressure and cold-

49 temperature using sapphire cell and jets experiments with gas-saturated petroleum (Aman et al.,

50 2015, Malone et al. 2018). Improvement to the understanding of DSD in the jet plume and

51 subsurface layer was set as a top priority to inform oil spill models (Malone et al. 2018; Lehr and

52 Socolofsky 2020). However, regardless of the d50, the importance of the fundamental shape, that is

53 the probability distribution function (PDF) of the DSD, on the rise of the oil from deep-sea blowout

54 and on its transport has been, so far, overlooked; our study fills this gap. 
Faillettaz et al. 2021 - Marine Pollution Bulletin - doi : 10.1016/j.marpolbul.2020.111920

While analytical methods predicted a large range of droplet sizes (up to $2.5 \mathrm{~mm}$, Gros et al. 2017; e.g. Figure 1a), scaled-up laboratory experiments based on turbulent dissipation rates (TDR, Aman et al. 2005; Pesch et al. 2020a) estimated at the Macondo riser-pipe found smaller droplets $(<500$ $\mu \mathrm{m}$, e.g. Figure 1b), similar to lognormal DSD acquired during the few dive operations in the deep plume $(1100 \mathrm{~m})$ and in deeper waters at $1400 \mathrm{~m}$ (Li et al. 2015, Spaulding et al., 2015). Regardless of the estimated median droplet size, there is so far no consistency on the PDF of the oil DSD. Although the most commonly assumed PDFs such as lognormal (LN) and Rosin-Rammler (RR) are fairly similar in shape, their distributions' edges drastically differ (Figure 1). Here, we quantify the difference in proportion of oil mass rising at the surface, sedimented on the seafloor, and beached on the shoreline focusing on the importance of the distribution function of the droplet size rather than the d50. We generated two hypothetical cases in which oil droplets ranged from 1 to $2400 \mu \mathrm{m}$ (case $1, \mathrm{~d} 50=900 \mu \mathrm{m})$ and from 1 to $500 \mu \mathrm{m}$ (case 2, d50 = $117 \mu \mathrm{m})$, derived from two published studies which used different droplet models, Gros et al. (2017) and Aman et al. (2015), respectively. We kept the d50 and the droplet size ranges similar among cases, which thus only differed by their PDF (Figure 1a,c). For both cases, one dynamic probability distribution function from the simulation model VDROP-J obtained from Gros et al. (2017) was used as baseline, and two theoretical distribution functions, the lognormal and Rosin-Rammler distributions, were fitted to the DSDs from VDROP-J using the R package fitdistrplus (Delignette-Muller and Dutang, 2015). The standard deviation and scale parameters were extracted from the lognormal and Rosin-Rammler fits, and used to generate the new lognormal and Rosin-Rammler DSDs. The DSD parameters are: d50 set to $900 \mu \mathrm{m}$ and $117 \mu \mathrm{m}, \log (\mathrm{SD})$ set to 0.3920 and 0.4297 for the lognormal, and shape set to 3.5010 and 3.3110 for the case 1 and case 2, respectively).

In a first approach, considering idealized conditions, we estimated the maximum potential effect of the choice of DSD on the rising speed and surfacing time of the oil droplets. We applied an integrated formulation of buoyant velocity from Zheng and Yapa (2000). The critical diameter $\mathrm{d}_{\mathrm{c}}$, beyond which Stokes's law does not apply (i.e., Reynolds number $>1$ ), which is defined as:

$$
d_{c}=\frac{9.52 \mu^{2 / 3}}{(g \rho \Delta \rho)^{1 / 3}}
$$


Faillettaz et al. 2021 - Marine Pollution Bulletin - doi : 10.1016/j.marpolbul.2020.111920

where $\mu$ is the dynamic viscosity of the ambient fluid, $g$ the gravitational acceleration

$\left(g=9.8 \mathrm{~m} \mathrm{~s}^{-2}\right), \rho$ is the ambient fluid density and $\Delta \rho$ is the absolute difference of density between

oil and seawater. If the spherical droplet diameter is smaller than $d_{C}$, then the terminal velocity

$\left(U_{T}\right)$ of the droplet is:

$$
U_{T}=\frac{g d^{2} \Delta \rho}{18 \mu}
$$

When the droplet spherical diameter is larger than $\mathrm{d}_{\mathrm{c}}$, the terminal velocity of droplets is approximated as:

$$
U_{T}=\left(\frac{8 g d \Delta \rho}{3 \rho}\right)^{1 / 2}
$$
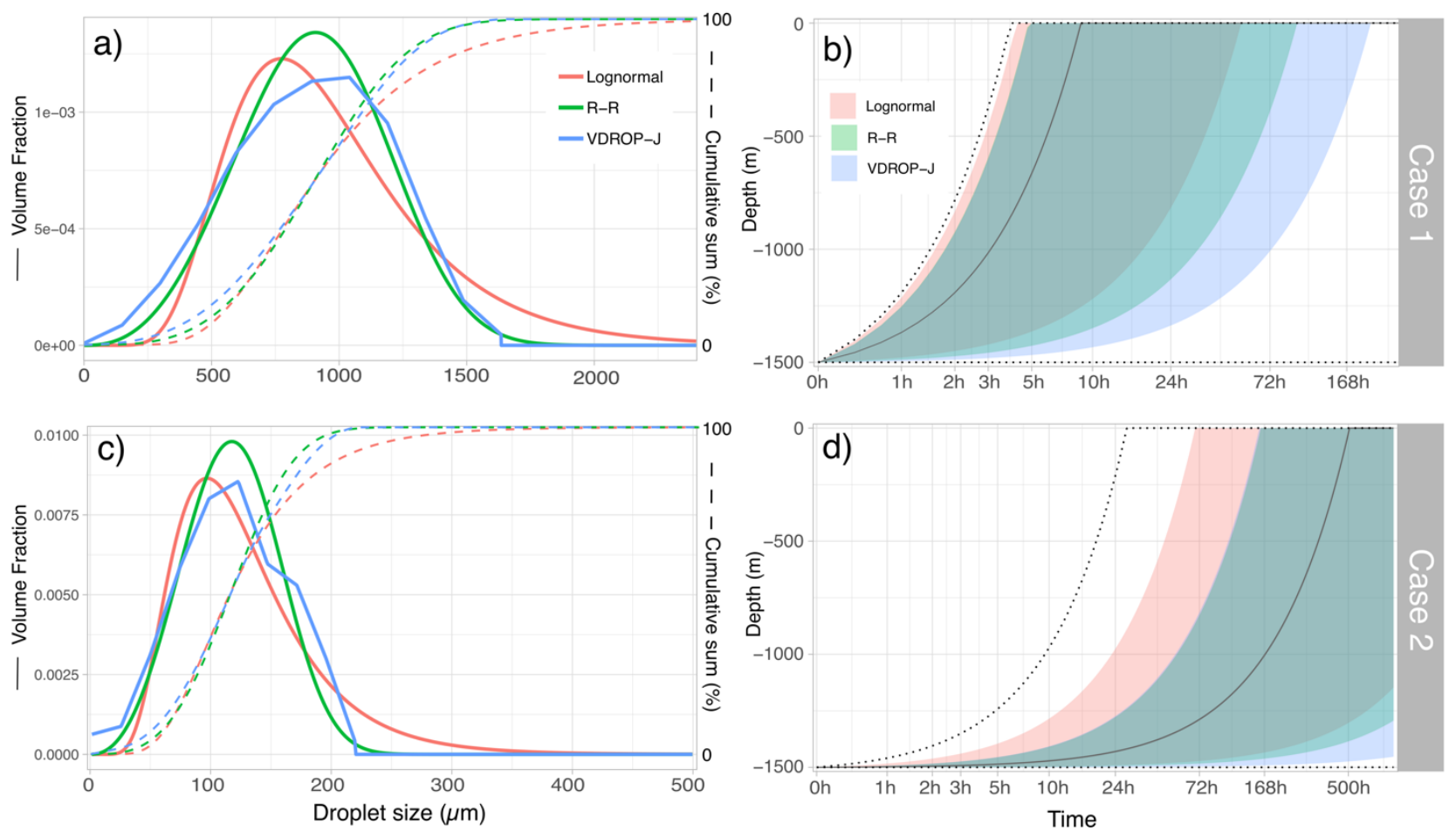

Figure 1. Distribution, cumulative sum and timing of surfacing of different analytical, Lognormal and Rosin-Rammler (R-R) droplet size distributions (DSD) fitted on two cases with different $\mathbf{d 5 0}$ and size ranges (case 1, size range and d50 from Gros et al. 2017 and case 2 from Aman et al. 2015). a) Probability distribution functions from VDROP-J (blue) and the fitted lognormal (red) and R-R (green) theoretical distribution laws for the hypothetical case 1 (solid lines) and cumulative sums highlighting that all share the same d50 (dashed lines). b) Oil droplets' vertical distribution for the various DSDs when released at the approximate depth $(1500 \mathrm{~m})$ and 
100

temperature $\left(4^{\circ} \mathrm{C}\right)$ of the Macondo well for the case 1 (upper depth: quantile 99\%, solid lines: median, lower depth: quantile 1\%) over time (x-axis is log $1 \mathrm{p}$-transformed). The dashed lines show the minimum and maximum depth of the oil droplets. c) and d) Same as a) and b) but for case 2 . The median droplet depths are similar among PDFs because they have the same d50.

Differences in the rise velocities of the bulk of the oil were comparable, as expected from the design of the simulations which focused on the tails of the PDFs rather than the d50. However, solely based on the differences between the PDF of the DSD, the rising time of the largest droplets (quantile 99\%) differed by up to $17.7 \%$ (45 min) for case 1 (Lognormal vs. VDROP-J; Figure $1 \mathrm{~b}$ ), and by as much as $127.1 \%(88 \mathrm{~h})$ for case 2 (Figure 1d). While for the smallest droplets (quantile 1\%), rising time would vary by up to $325.2 \%(167.5 \mathrm{~h})$ for the case 1 (Figure 1b), and by over 5 -fold for the case 2 (Figure 1d). The estimated rising velocities of the different quantiles are provided in the Supplementary Information (Table S1). The surfacing time of the lognormal and Rosin-Rammler DSDs from case 1 with a d50 of $900 \mu \mathrm{m}$ (minimum surfacing time of $4 \mathrm{~h}, 8.75 \mathrm{~h}$ for $50 \%$ and $51.55 \mathrm{~h}$ for $99 \%$ of the oil) matches the estimates without subsea dispersant injection (SSDI) at the Macondo wellhead from Testa et al. (2016) and Gros et al. (2017) that suggest that all the oil reached the surface within $7 \mathrm{~h}$ for the largest droplets. In our idealized conditions with the same d50, the lower tail of the VDROP-J DSD requires an extra $125.25 \mathrm{~h}$ to surfacing as compared to the Rosin-Rammler DSD and $167.5 \mathrm{~h}$ compared to the lognormal one (Figure $1 \mathrm{~b}$ ). For the case 2, with a d50 of $117 \mu \mathrm{m}$, the relative anomalies of surfacing time are higher among the different PDFs due to the wider range of surfacing time compared to case 1 . This long surfacing time results from the small d50 and the omission of internal degassing process, whereby the multiphase droplet ascent accelerates as its gas-phase expands with decreasing hydrostatic pressure (Pesch et al. 2018, 2020b). Notably, the lognormal distribution differs the most from the Rosin-Rammler and VDROP-J PDFs (Figure 1b,d). Our idealized conditions results are also in line with the predominating importance of the d50 for the median surfacing time of oil droplets, with longer surfacing time for smaller d50s (Paris et al. 
Faillettaz et al. 2021 - Marine Pollution Bulletin - doi : 10.1016/j.marpolbul.2020.111920

2012; Socolofsky et al. 2019), yet they still show that the choice of distribution function has notable influence.

We then applied the same approach of comparing different outputs by only varying the PDF in a more realistic application to the DWH oil spill. We used a four-dimension Lagrangian framework, the Connectivity Modeling System (CMS; Paris et al. 2013), in which the DSDs are deployed in simulations configured with the DWH initial conditions as described in Perlin et al. (2020). In short, the CMS oil application performs Lagrangian particle tracking of oil droplets released in the far-field at the trap height, approximately $300 \mathrm{~m}$ above the wellhead (Socolofsky et al. 2011). Particle transport calculations take into account 3D ocean currents, wind drift, temperature, salinity, multi-fraction droplet density, droplet size evolution due to partitioning and biodegradation, and surface oil evaporation (Paris et al. 2012; Le Henaff et al. 2012; LindoAtichati et al. 2016; Perlin et al. 2020). The 4th order Runge-Kutta integration scheme forms the basis for particle advection in the model, while a random walk model represents sub-grid scale turbulent diffusion (Paris et al. 2013). In our simulations, the vertical and horizontal diffusivities coefficients were based on the empirical approximations from Paris et al. (2012) and set to 10${ }^{5} \mathrm{~m}^{2} \mathrm{~s}^{-1}$ and $1 \mathrm{~m}^{2} \mathrm{~s}^{-1}$. Computations of the vertical terminal velocity of a droplet are based on its density and size, its Reynolds number, as well as on other ambient conditions such as water temperature, salinity, density, and kinematic viscosity (Zheng et al. 2003, Paris et al. 2012). Fluid flow includes a release of 3000 oil droplets at the trap height every 2 hours for 87 days until July 15, 2010 - the day of successful containment of the spill using a capping stack. The release location is $28.736^{\circ} \mathrm{N}, 88.365^{\circ} \mathrm{W}$ at $1222 \mathrm{~m}$, i.e., the estimated height of oil and gas separation $300 \mathrm{~m}$ above the wellhead (Socolofsky et al. 2011). The oil droplets were tracked for total of 167 days from the initial blowout date, and the surface oil mass (in the layer $0-1 \mathrm{~m}$ ) and the sedimented and beached oil mass were computed for each $0.1^{\circ} \times 0.1^{\circ}$ spatial bin over the entire span of the oil spill. Here, oil concentrations are estimated by post-processing, and the six scenarios of DSD presented in Figure 1 were carried out using two model simulations: the first with oil droplets ranging from 1 to $2400 \mu \mathrm{m}$ (case 1) and the second with oil droplets ranging 
Faillettaz et al. 2021 - Marine Pollution Bulletin - doi : 10.1016/j.marpolbul.2020.111920

from 1 to $500 \mu \mathrm{m}$ (case 2). We then computed differences in the sedimented and beached oil mass and of the surface oil mass between the three scenarios of DSD for each simulation.

As expected, the differences are once again highly sensitive to the $\mathrm{d} 50$ and the size range of the oil droplet modeled. The total combined mass of oil that beached and sedimented was indeed higher by $45.29 \%$ (187,996 tons versus 129,394 tons), $43.83 \%$ (185,595 tons versus 129,038 tons) and 50.68\% (195,052 tons versus 129,444 tons) with the smaller range of oil droplet sizes and d50 (case 2) compared to the larger ones (case 1) for the lognormal, Rosin-Rammler and VDROP-J DSDs, respectively. Yet, the choice of the DSD's PDF played an important role within each case. When comparing the proportion of oil mass that beached over the oil mass that sedimented, the vast majority of the oil beached in case 1 (i.e. large d50) and the choice of PDF had a relatively limited influence on these outputs: only $3.210^{-5} \%$ of the oil sedimented over the oil that beached with the lognormal distribution, $0.1 \%$ with the Rosin-Rammler, and $1.10 \%$ with the VDROP-J distribution used here. Yet the ratios of beached versus sedimented oil mass estimates for this case are far below the $21 \pm 10 \%$ sedimentation rate quantified for the DWH oil spill (Joye et al. 2016, Romero et al. 2017). For case 2 of the smaller oil droplets size range, this ratio was reversed and the differences were closer to empirical values: the oil sedimented 2.08 times more than it beached with a lognormal DSD (126,978 tons sedimented vs. 61,018 tons beached), 2.11 times more with a Rosin-Rammler (126,094 tons vs. 59,501 tons), and 2.32 times more with the DSD modeled from VDROP-J (136,318 tons vs. 58,735 tons). The DSD with the larger d50 therefore predicts that almost no oil sedimented on the seafloor while most oil reached the surface and then drifted to the coast, with a total mass of beached oil twice as higher compared to the scenario with the smaller d50. This difference also reflects high surface evaporation rates (de Gouw et al. 2011), affecting mostly the largest droplets since they rise faster. Interestingly, the total oil mass from case 2 that sedimented is on the same order of magnitude than the oil that beached in case 1, highlighting that the predictions of oil mass beached versus sedimented is critically important for evaluation response's tradeoff (Murawski et al. 2019). 
Faillettaz et al. 2021 - Marine Pollution Bulletin - doi : 10.1016/j.marpolbul.2020.111920

183

184

The proportions of beached versus sedimented oil mass on the seafloor are markedly different between cases and distribution functions of the DSDs, but the spatial distribution of these differences is perhaps more informative. With the larger droplets (case 1), the major differences in surface oil concentration occur close to the blowout, 50-100 km to the ESE of the well, and at the edge of the distribution in the western Gulf of Mexico, over the West Florida shelf (Figure 2, left panels). The lognormal DSD leads to lower surface oil mass near the well and higher oil mass in the West Bay of Louisiana compared to the Rosin-Rammler and VDROP-J PDFs (Figure 2 and Fig. S2, left panels). The DSDs based on Rosin-Rammler and VDROP-J provide very similar results for this size range (i.e. 1-2400 $\mu \mathrm{m}$ ), with VDROP-J showing the highest surface concentrations overall, in particular over the West Florida Shelf and western Gulf of Mexico (Figure 2 and Fig. S2). Considering a Rosin-Rammler distribution instead of a lognormal DSD increases the sedimentation near the blowout location, and also towards the West Florida slope while it reduces the beached oil along Louisiana, Mississippi and Alabama coastline (Figure 2b and Fig. S2b). Using DSD modeled from VDROP-J increases the sedimentation of oil near the well relatively to the lognormal and Rosin-Rammler DSD, while beaching increases in the western Gulf of Mexico and along the Florida Panhandle, with local differences of beached oil mass of up to 641 tons per $0.1^{\circ} \times 0.1^{\circ}$ bin (ca. 5.9 tons $/ \mathrm{km}^{2}$; Fig. S2). While the overall patterns were fairly similar between the VDROP-J and Rosin-Rammler distributions, the beaching was lower along the coast of Louisiana and Mississippi and East Florida compared to the lognormal DSD in both cases, except east of the Louisiana Peninsula (Figure 2b,f and Fig. S2b,f). 

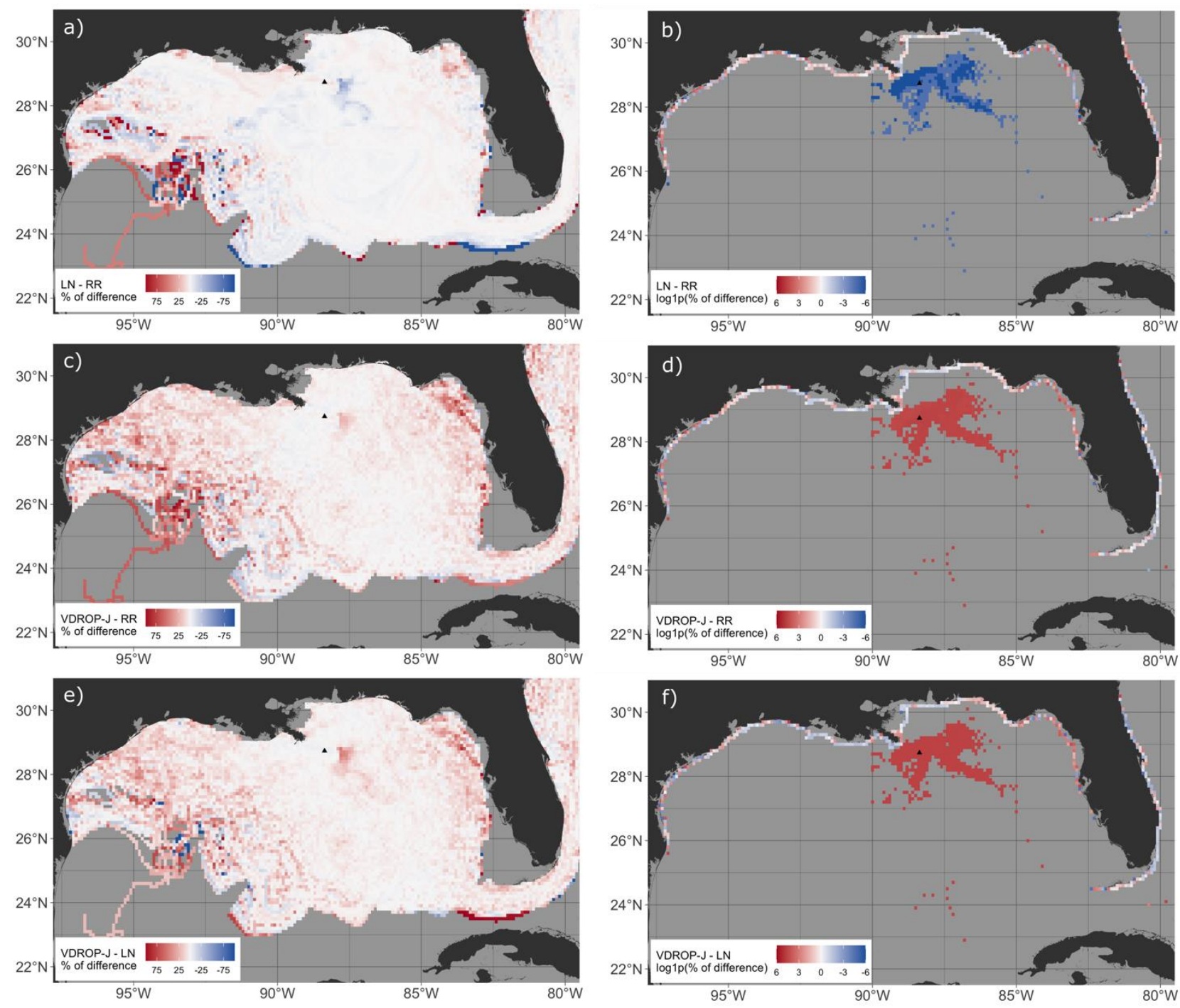

Figure 2. (a) Maps of surface (0-1 m) oil mass differences between lognormal (LN) and

Rosin-Rammler (RR), (c) VDROP-J and RR, (e) VDROP-J and LN, and (b) sedimented oil mass differences between LN and RR, (d) VDROP-J and RR, and (f) VDROP-J and LN for oil droplet sizes in the range $1-2400 \mu \mathrm{m}$ (case 1) for the three DSD presented on Fig. 1a.

212 The differences generated by the choice of DSD functions are more marked when considering 213 smaller oil droplets $(<500 \mu \mathrm{m}$; case 2$)$. While the proportions of differences are lower than for 214 case 1 per se (generally $\leq 100 \%$ ), the differences in the total mass of oil are considerable and 215 surprising for the same d50: up to over 400 tons of surface oil and $>4,000$ tons of sedimented oil 216 per $0.1^{\circ} \times 0.1^{\circ}$ bins, respectively, which represents a difference of $c a .38 .5$ tons of oil per $\mathrm{km}^{2}$

217 (Fig. S3). Spatially, the Rosin-Rammler DSD predicts the lowest surface oil amount north of the 218 Macondo well (Figure 3a,c). Here again, the largest relative differences occur at the edges of the 
Faillettaz et al. 2021 - Marine Pollution Bulletin - doi : 10.1016/j.marpolbul.2020.111920

219 distribution, for each of the three DSDs. One notable difference is also found around the

220 Macondo well area, where the lognormal distribution predicts higher surface oil mass compared 221 to VDROP-J and Rosin-Rammler DSDs immediately above and up to $60 \mathrm{~km}$ towards the North 222 and South (Figure 3a,e). The masses of beached and sedimented oil resulting from a lognormal 223 DSD (61,019 tons and 126,989 tons, respectively) are comparable to a Rosin-Rammler 224 distribution (59,501 tons and 126,094 tons, respectively) but the spatial distribution patterns are 225 notably different: the lognormal DSD leads to increased beached oil mass in the western Gulf, 226 along the Louisiana, Mississippi, Alabama and westernmost Florida coasts, and in the domain's 227 edges (Figure 3b), and higher sedimentation in the Macondo area expect within $50 \mathrm{~km}$ to the east 228 of the well is lower with the latter (Figure $3 b$ ). Noteworthy differences also emerged with the 229 VDROP-J that increased sedimentation south and west of the well compared to both the 230 lognormal and Rosin-Rammler DSDs (Figure 3d,f and Fig. S3d,f). More oil beached along the 231 west coasts of the Gulf compared to the Rosin-Rammler, and both the west and east Gulf coasts 232 compared to the lognormal, while less oil reached the coasts of Louisiana and Mississippi 233 (Figure $3 \mathrm{f}$ and Fig. S3f). Overall, the results show that the area near the Macondo well and the 234 coastline around the Mississippi delta - the areas most impacted by the oil spill (Nixon et al. 235 2016) - are the areas where most differences emerge based on the DSD considered. 

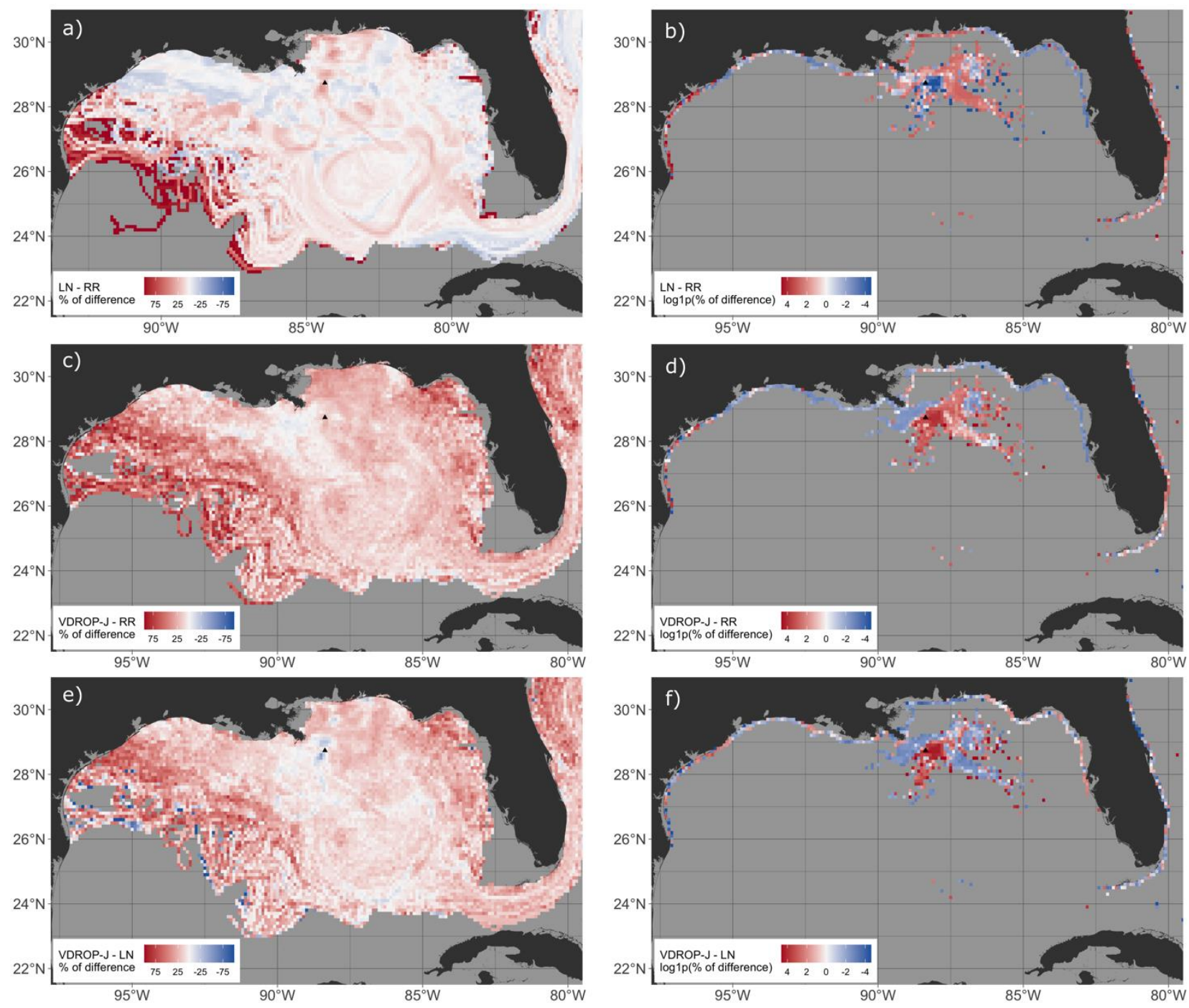

237 Figure 3. (a) Maps of surface (0-1 m) oil mass differences between lognormal (LN) and

238 Rosin-Rammler (RR), (c) VDROP-J and RR, (e) VDROP-J and LN, and (b) sedimented oil mass differences between LN and RR, (d) VDROP-J and RR, and (f) VDROP-J and LN for

oil droplet sizes in the range 1-500 $\mu \mathrm{m}$ (case 2) for the three DSD presented on Fig. $1 \mathrm{~b}$.

This study focuses on the critical choice of the DSD's PDF for modeling the transport and fate of uncontrolled deep-sea oil spills. To determine optimal oil spill responses and access tradeoffs, different scenarios are typically weighted, including considering the application of surface and/or subsea chemical dispersants (Xu et al. 2019, Murawski et al. 2019). Here, we demonstrate that, even with similar d50, the surfacing time (Figure 1b,d), the distance travelled by droplets, and the patterns of sedimented and beached oil (Figure $2 \& 3$ ) will vary based on the two PDFs most frequently used for modeling the DSD during deeps oil spills, lognormal and Rosin- 
Faillettaz et al. 2021 - Marine Pollution Bulletin - doi : 10.1016/j.marpolbul.2020.111920

Rammler (Wang and Calabrese 1986, Spaulding et al. 2015, NASEM 2019). The larger divergences in patterns of surface, sedimented, and beached oil mass and ratios occur between the theoretical DSDs and the modeled non-fundamental DSD from VDROP-J (Figures 1b,d,2 \& 3). Therefore, in the absence of robust observations of the DSD in the water column, sensitivity and uncertainty analyses should thus consider not only different d50, but also both of the most characteristic probability distribution functions of the DSD for far-field modeling.

Differences in oil transport and fate are found between all three distributions (i.e., lognormal, Rosin-Rammler, and non-fundamental VDROP-J). Our results suggest that for both d50 considered in cases 1 and 2, the lognormal DSD qualitatively matches better the observed patterns of sedimented oil mass, with higher residual hydrocarbons in the sediment to the west and north of the Macondo well and on the coasts and wetlands of Louisiana, Mississippi and Alabama, and less landfall on the West Florida Shelf (Le Hénaff et al. 2012; Boufadel et al. 2014; Nixon et al. 2016; Romero et al. 2017). A better fit with the lognormal distribution has also been suggested by laboratory (Malone et al., 2018) and field observations (Spaulding et al., 2015). In conclusion, the choice of DSD function, regardless of the d50, is not trivial as it has large consequences on the distribution of oil concentration in the water column, sediment and shoreline. For the DWH, major differences occur at the edge of the oil distribution, which is of remarkable importance since toxic oil concentrations were present in these regions, yet invisible to satellite imagery (Berenshtein et al. 2020). Given the rapid advances in oil spill research following DWH, extending hindcast modeling approaches to consider a range of characteristic DSDs functions (d50 and PDFs) are needed to ultimately help predict the distribution of oil mass and evaluating the response tradeoffs in any future deep-sea spill and response measures (Malone et al. 2020, Murawski et al. 2019).

\section{ACKNOWLEDGEMENTS}

We thank the three reviewers for their thorough and helpful comments. This research was made possible by a grant from the Gulf of Mexico Research Initiative (GOMRI) C-IMAGE III and 
Faillettaz et al. 2021 - Marine Pollution Bulletin - doi : 10.1016/j.marpolbul.2020.111920

RECOVER2 Consortia. Data are publicly available through the Gulf of Mexico Research Initiative Information and Data Cooperative (GRIIDC), DOI: 10.7266/EZYAADMS;

https://data.gulfresearchinitiative.org/data/R6.x804.000:0062.

\section{REFERENCES}

Aman, Z.M., Paris, C.B., May, E.F., Johns, M.L., Lindo-Atichati, D., 2015. High-pressure visual experimental studies of oil-in-water dispersion droplet size. Chem. Eng. Sci. 127, 392-400. https://doi.org/10.1016/j.ces.2015.01.058

Berenshtein, I., Paris, C.B., Perlin, N., Alloy, M.M., Joye, S.B., Murawski, S., 2020. Invisible oil beyond the Deepwater Horizon satellite footprint. Sci. Adv. 6, 1-12. https://doi.org/10.1126/sciadv.aaw8863

Boufadel, M.C., Abdollahi-Nasab, A., Geng, X., Galt, J., Torlapati, J., 2014. Simulation of the landfall of the deepwater horizon oil on the shorelines of the Gulf of Mexico. Environ. Sci. Technol. 48, 9496-9505. https://doi.org/10.1021/es5012862

Chan, G.K.Y., Chow, A.C., Adams, E.E., 2015. Effects of droplet size on intrusion of subsurface oil spills. Environ. Fluid Mech. 15, 959-973. https://doi.org/10.1007/s10652-014-9389-5 de Gouw, J.A., Middlebrook, A.M., Warneke, C., Ahmadov, R., Atlas, E.L., Bahreini, R., Blake, D.R., Brock, C.A., Brioude, J., Fahey, D.W., Fehsenfeld, F.C., Holloway, J.S., Le Henaff, M., Lueb, R.A., McKeen, S.A., Meagher, J.F., Murphy, D.M., Paris, C., Parrish, D.D., Perring, A.E., Pollack, I.B., Ravishankara, A.R., Robinson, A.L., Ryerson, T.B., Schwarz, J.P., Spackman, J.R., Srinivasan, A., Watts, L.A., 2011. Organic Aerosol Formation Downwind from the Deepwater Horizon Oil Spill. Science. 331, 1295-1299. https://doi.org/10.1126/science.1200320

Delignette-Muller, M. L., Dutang, C., 2015. fitdistrplus: An R Package for Fitting Distributions. Journal of Statistical Software, 64(4), 1-34. URL: http://www.jstatsoft.org/v64/i04/.

Gros, J., Socolofsky, S.A., Dissanayake, A.L., Jun, I., Zhao, L., Boufadel, M.C., Reddy, C.M., Arey, J.S., 2017. Petroleum dynamics in the sea and influence of subsea dispersant injection during Deepwater Horizon. Proc. Natl. Acad. Sci. 114, 10065-10070. https://doi.org/10.1073/pnas.1612518114 
Faillettaz et al. 2021 - Marine Pollution Bulletin - doi : 10.1016/j.marpolbul.2020.111920

305

306

Johansen, Ø., Brandvik, P.J., and Farooq. U., 2013. Droplet breakup in subsea oil releases - Part 2: Predictions of droplet size distributions with and without injection of chemical dispersants. Mar. Pollut. Bull. 73, 327-335. https://doi.org/10.1016/j.marpolbul.2013.04.012

Joye S.B., Bracco, A., Özgökmen, T.M., Chanton, J.P., Grosell, J.P., MacDonald, J.P. et al. (2016) The Gulf of Mexico ecosystem, six years after the Macondo oil well blowout. Deep-Sea Res. Part II, 129, 4-19. https://doi.org/10.1016/j.dsr2.2016.04.018

Le Hénaff, M., Kourafalou, V.H., Paris, C.B., Helgers, J., Aman, Z.M., Hogan, P.J., Srinivasan, A., 2012. Surface evolution of the deepwater horizon oil spill patch: Combined effects of circulation and wind-induced drift. Environ. Sci. Technol. 46, 7267-7273. https://doi.org/10.1021/es301570w

Lehr W., Socolofsky S.A. 2020. The Importance of Understanding Fundamental Physics and Chemistry of Deep Oil Blowouts. In: Murawski S. et al. (eds) Deep Oil Spills. Springer, Cham. p. 14-24.

Li, Z., Bird, A., Payne, J., Vinhateiro, N., Kim, Y., Davis, C., Loomis, N., 2015. Technical Reports for Deepwater Horizon Water Column Injury Assessment: Oil Particle Data from the Deepwater Horizon Oil Spill. RPS ASA 55 Village Square Drive, South Kingstown, RI 02879. Li, Z., Spaulding, M.L., and French-McCay, D., 2017. An algorithm for modeling entrainment and naturally and chemically dispersed oil droplet size distribution under surface breaking wave conditions. Mar. Pollut. Bull., 119, 45-152, doi:10.1016/j.marpolbul.2017.03.048

Lindo-Atichati D, Paris C.B., Le Hénaff M., Schedler M., Valladares Juárez A.G., Müller R., 2016. Simulating the effects of droplet size, high-pressure biodegradation, and variable flow rate on the subsea evolution of deep plumes from the Macondo blowout, Deep Sea Research, doi:10.1016/j.dsr2.2014.01.011

Malone, K., Aman, Z. M., Pesch, S., Schlüter, M., Krause, D., 2020. Jet formation at the spill site and resulting droplet size distributions. In Deep Oil Spills, Springer. pp. 43-64.

Malone, K., Pesch, S., Schlüter, M., Krause, D., 2018. Oil Droplet Size Distributions in DeepSea Blowouts: Influence of Pressure and Dissolved Gases. Environ. Sci. Technol. 52, 63266333. https://doi.org/10.1021/acs.est.8b00587 
Faillettaz et al. 2021 - Marine Pollution Bulletin - doi : 10.1016/j.marpolbul.2020.111920

333 Murawski, S.A., Schlüter, M., Paris, C.B., Aman, Z.M., 2019. Resolving the dilemma of

334 dispersant use for deep oil spill response. Environ. Res. Lett. 14, 091002.

335 https://doi.org/10.1088/1748-9326/ab3aa0

336 National Academies of Sciences and Medicine, E., 2019. The Use of Dispersants in Marine Oil

337 Spill Response. The National Academies Press, Washington, DC.

338 https://doi.org/10.17226/25161

339 Nixon Z, Zengel S, Baker M, Steinhoff M, Fricano G, Rouhani S, et al. Shoreline oiling from the 340 Deepwater Horizon oil spill. Mar Pollut Bull. 2016; 107: 170-178.

341 doi:10.1016/j.marpolbul.2016.04.003

342 Paris, C.B., Berenshtein, I., Trillo, M.L., Faillettaz, R., Olascoaga, M.J., Aman, Z.M., Schlüter, 343 M., Boye, S. B., 2018. BP Gulf Science Data Reveals Ineffectual Subsea Dispersant Injection for 344 the Macondo Blowout. Front Mar Sci. 5:389. doi:10.3389/fmars.2018.00389

345 Paris, C.B., Le Hénaff, M., Aman, Z.M., Subramaniam, A., Helgers, J., Wang, D.-P., 346 Kourafalou, V.H., Srinivasan, A., 2012. Evolution of the Macondo Well Blowout: Simulating 347 the Effects of the Circulation and Synthetic Dispersants on the Subsea Oil Transport. Environ. 348 Sci. Technol. 46, 13293-13302. https://doi.org/10.1021/es303197h

349 Paris, C.B., Helgers, J., van Sebille, E., Srinivasan, A., 2013. Connectivity Modeling System: A 350 probabilistic modeling tool for the multi-scale tracking of biotic and abiotic variability in the 351 ocean. Environ. Model. Softw. 42, 47-54. https://doi.org/10.1016/j.envsoft.2012.12.006

352 Perlin, N., Paris, C.B., Berenshtein, I., Vaz, A.C., Faillettaz, R., Aman, Z.M., Schwing, P.T., 353 Romero, I.C., Schlüter, M., Liese, A., 2020. Far-Field Modeling of a Deep-Sea Blowout: 354 Sensitivity Studies of Initial Conditions, Biodegradation, Sedimentation, and Subsurface 355 Dispersant Injection on Surface Slicks and Oil Plume Concentrations, in: Deep Oil Spills. 356 Springer, pp. 170-192.

357 Pesch, S.; Jaeger, P.; Jaggi, A.; Malone, K.; Hoffmann, M.; Krause, D.; Oldenburg, T.B.P.; 358 Schlüter, M., 2018. Rise Velocity of Live-Oil Droplets in Deep-Sea Oil Spills. Env. Engine. Sci. $35935(4), 289-299$. 
Faillettaz et al. 2021 - Marine Pollution Bulletin - doi : 10.1016/j.marpolbul.2020.111920

Pesch S, Knopf R, Radmehr A, Paris CB, and Aman ZM, Hoffmann M, Schlüter M. 2020a Experimental investigation, scale-up and modeling of droplet size distributions in turbulent multiphase jets, Multiphase Science and Technology, 32(2):113-136

Pesch, S.; Schlüter, M.; Aman, Z.M.; Malone, K.; Krause, D.; Paris, C.B., 2020b. Behavior of Rising Droplets and Bubbles: Impact on the Physics of Deep-Sea Blowouts and Oil Fate. In: Murawski, S.A.; Ainsworth, C.H.; Gilbert, S.; Hollander, D.J.; Paris, C.B.; Schlüter, M.; Wetzel, D.L. (eds.). Deep Oil Spills - Facts, Fate and Effects. Springer Nature Switzerland, 65-82.

Romero, I.C., Toro-Farmer, G., Diercks, A.R., Schwing, P., Muller-Karger, F., Murawski, S., Hollander, D.J., 2017. Large-scale deposition of weathered oil in the Gulf of Mexico following a deep-water oil spill. Environ. Pollut. 228, 179-189. https://doi.org/10.1016/j.envpol.2017.05.019

Ryerson, T.B., Camilli, R., Kessler, J.D., Kujawinski, E.B., Reddy, C.M., Valentine, D.L., Atlas, E., Blake, D.R., De Gouw, J., Meinardi, S., Parrish, D.D., Peischl, J., Seewald, J.S., Warneke, C., 2012. Chemical data quantify Deepwater Horizon hydrocarbon flow rate and environmental distribution. Proc. Natl. Acad. Sci. U. S. A. 109, 20246-20253. https://doi.org/10.1073/pnas.1110564109

Socolofsky, S.A., Adams, E.E., Boufadel, M.C., Aman, Z.M., Johansen, Ø., Konkel, W.J., Lindo, D., Madsen, M.N., North, E.W., Paris, C.B., Rasmussen, D., Reed, M., Rønningen, P., Sim, L.H., Uhrenholdt, T., Anderson, K.G., Cooper, C., Nedwed, T.J., 2015. Intercomparison of oil spill prediction models for accidental blowout scenarios with and without subsea chemical dispersant injection. Mar. Pollut. Bull. 96, 110-126.

https://doi.org/10.1016/j.marpolbul.2015.05.039

Socolofsky, S.A., Adams, Sherwood, C,R., 2011. Formation dynamics of subsurface hydrocarbon intrusions following the Deepwater Horizon blowout, Geophy. Res. Let., 8, L09602, doi:10.1029/2011GL047174, 2011

Socolofsky, S.A., Gros, J., North, E., Boufadel, M.C., Parkerton, T.F., Adams, E.E., 2019. The treatment of biodegradation in models of sub-surface oil spills: A review and sensitivity study. Mar. Pollut. Bull. 143, 204-219. https://doi.org/10.1016/j.marpolbul.2019.04.018

Spaulding, M., Li, Z., Mendelsohn, D., Crowley, D., French-McCay, D., Bird, A., 2017. Application of an Integrated Blowout Model System, OILMAP DEEP, to the Deepwater 
This work is licensed under a CC-BY-NC-ND 4.0 license.

Faillettaz et al. 2021 - Marine Pollution Bulletin - doi : 10.1016/j.marpolbul.2020.111920

Horizon (DWH) Spill. Mar. Pollut. Bull. 120, 37-50.

\section{https://doi.org/10.1016/j.marpolbul.2017.04.043}

Spaulding, M., Mendelsohn, D., Crowley, D., Li, Z., Bird, A., 2015. DRAFT Technical Reports for Deepwater Horizon Water Column Injury Assessment.

Tambe, D.E., Sharma, M.M., 1994. The effect of colloidal particles on fluid-fluid interfacial properties and emulsion stability. Adv. Colloid Interface Sci. 52, 1-63. https://doi.org/10.1016/0001-8686(94)80039-1

Testa, J.M., Eric Adams, E., North, E.W., He, R., 2016. Modeling the influence of deep water application of dispersants on the surface expression of oil: A sensitivity study. J. Geophys. Res. Ocean. 121, 5995-6008. https://doi.org/10.1002/2015JC011571

Wang, C.Y., Calabrese, R. V., 1986. Drop breakup in turbulent stirred- tank contactors. Part II:

Relative influence of viscosity and interfacial tension. AIChE J. 32, 667-676. https://doi.org/10.1002/aic.690320417

Xu, C., Lin, P., Zhang, S., Sun, L., Xing, W., Schwehr, K.A., Chin, W.-C., Wade, T.L., Knap, A.H., Hatcher, P.G., Yard, A., Jiang, C., Quigg, A., Santschi, P.H., 2019. The interplay of extracellular polymeric substances and oil/Corexit to affect the petroleum incorporation into sinking marine oil snow in four mesocosms. Sci. Total Environ. 693, 133626. https://doi.org/10.1016/j.scitotenv.2019.133626

Zhao, L., Shaffer, F., Robinson, B., King, T., D'Ambrose, C., Pan, Z., Gao, F., Miller, R.S., Conmy, R.N., Boufadel, M.C., 2016. Underwater oil jet: Hydrodynamics and droplet size distribution. Chem. Eng. J. 299, 292-303. https://doi.org/10.1016/j.cej.2016.04.061

Zhao L, Boufadel MC, Socolofsky SA, Adams E, King T, Lee K. Evolution of droplets in subsea oil and gas blowouts: Development and validation of the numerical model VDROP-J. Mar Pollut Bull. 2014;83: 58-69. doi:10.1016/j.marpolbul.2014.04.020

Zheng L, Yapa PD. 2000. Buoyant velocity of spherical and nonspherical bubbles/droplets. J Hydraul Eng.;126: 852-854.

Zheng, L., Yapa, P.D., Chen, F., 2003. A model for simulating deepwater oil and gas blowouts Part I: Theory and model formulation. J. Hydraul. Res. 41, 339-351. 
This work is licensed under a CC-BY-NC-ND 4.0 license.

Faillettaz et al. 2021 - Marine Pollution Bulletin - doi : 10.1016/j.marpolbul.2020.111920

417 